\title{
Ventilatory response to exercise of elite soccer players
}

\author{
Adriano Di Paco ${ }^{1,2^{*}}$, Giosuè A Catapano ${ }^{3}$, Guido Vagheggini ${ }^{1,2}$, Stefano Mazzoleni ${ }^{2,4}$, Matteo Levi Micheli ${ }^{5}$ \\ and Nicolino Ambrosino ${ }^{1,2}$
}

\begin{abstract}
Background: The purpose of this study was to evaluate the role of ventilatory parameters in maximal exercise performance in elite soccer players.

Methods: From September 2009 to December 2012, 90 elite soccer players underwent evaluation of lung function test and ergospirometry by means of an incremental symptom-limited treadmill test. Results were analyzed according to i) maximal exercise velocity performed (Hi-M: high-performers, $>18.65$ km/h; Lo-M: low-performers, $<18.65$ km/h) and ii) usual role in the team.

Results: Hi-M showed higher peak minute ventilation ( $\dot{V} E_{\text {peak }}: 158.3 \pm 19.5$ vs $148.0 \pm 18.54 \mathrm{~L} / \mathrm{min}, \mathrm{p}=0.0203$ ), and forced expiratory volume at first second $(5.28 \pm 0.50$ vs $4.89 \pm 0.52$ liters, $p<0.001)$ than Lo-M, independently of playing role. Moreover, a significant correlation between peak oxygen uptake and $\dot{V} E(r=0.57, p<0.001)$ was found.

Conclusions: Ventilatory response plays a role in the assessment of exercise capacity in elite soccer players.
\end{abstract}

Keywords: Exercise testing, Field performance, Team sports, Training, Ventilatory parameters

\section{Background}

Playing soccer is the result of combination of technical, tactical, psychological and athletic skills. To assess soccer player performance model, studies have used match analysis systems [1-5], and laboratory and field tests [6-9]. Other studies addressed different roles [10,11], different data tests [12,13], and relationships between endurance field tests and match analysis data [14].

Soccer is a sport characterized by more than 1,000 unpredictable and acyclic changes in activity, each occurring every 3 to 5 seconds, involving up to 40 sprints, tackles and jumps per match [15]. Decelerations, kicking, dribbling, and tackling are additional actions required as well [16]. Therefore, the physical effort imposed on the players is elicited by all these gestures: as a consequence soccer is a highly physiologically demanding sport, with additional stress resulting by frequent matches and high load training sessions are quite high [17-21].

\footnotetext{
* Correspondence: dipaco69@gmail.com

${ }^{1}$ Pulmonary Rehabilitation and Weaning Center, Auxilium Vitae, Volterra, Pisa, Italy

${ }^{2}$ Rehabilitation Bioengineering Laboratory, ScuolaSuperioreSant'Anna and Auxilium Vitae, Volterra, Italy

Full list of author information is available at the end of the article
}

Computerized systems for time-motion analysis have shown that during a match elite soccer players are able to perform 2 to $3 \mathrm{~km}$ of high-intensity running (at a speed $>15 \mathrm{~km} / \mathrm{h})$ and about $0.6 \mathrm{~km}$ sprinting $(>20 \mathrm{~km} / \mathrm{h})$ : these distances are $28 \%$ and $58 \%$ respectively greater than those covered by intermediate level professional players [10]. Technical and tactical skills in soccer are highly dependent on the player physical capacity [22,23].

Relevant effort has been devoted to the evaluation of muscular strength, power, maximal speed, aerobic and anaerobic endurance, but poor attention has been addressed to ventilatory capacity. In most studies cardiorespiratory response to maximal exercise was evaluated using peak oxygen uptake ( $\left.\dot{V} \mathrm{O}_{2 p e a k}\right)$ and the corresponding anaerobic threshold value [23-31]. To the best of our knowledge, currently available studies do not focus on ventilatory function as evaluation tool of professional soccer players performance.

In the present study we hypothesized that ventilatory capacity can be a determinant of soccer players exercise capacity. In order to demonstrate our hypothesis the relationship between ventilatory parameters and exercise tolerance was evaluated in a group of elite Italian 
soccer players using an incremental symptom-limited cardiopulmonary exercise test on a treadmill. Several different measurements reflecting cardiovascular, respiratory, and metabolic response can be recorded during the exercise test. The assessment of ventilatory parameters can contribute to improve training programmes and, consequently, athletic performance.

\section{Methods}

\section{Subjects}

From 2009 to 2012, ninety professional soccer players from five Italian serie A soccer teams were evaluated in the period September-December of each year after completing pre-seasonal training programme in the frame of routine medical evaluations. Each subject provided informed signed consent to the use of their data for scientific purposes.

As expected, no player reported either smoking habit or any relevant disease, with negative chest physical examination. Players were unaware of the aim of the study and researchers performing analysis of results were blind to players' identity.

\section{Procedures \\ Lung function test}

Dynamic lung volumes were assessed by means of a pneumotachograph (V-Max Encore, Yorba Linda, CA, USA). Predicted values were those of American Thoracic Society [32]. Maximal Voluntary Ventilation (MVV) was estimated multiplying Forced Expiratory Volume at first second $\left(\mathrm{FEV}_{1}\right)$ value by 40 [33].

\section{Electrocardiography}

Resting and exercise electrocardiography (EKG) was assessed in upright position by means of a 10-lead electrocardiograph (Cardiosoft, GE medical systems, Fairfield, CT, USA) applied on the cardiac screening (six precordial leads) and the posterior wall of the chest (four peripheral leads).

\section{Exercise test}

An incremental symptom-limited exercise test was performed on a treadmill (Runrace 900, Technogym, Gambettola, Italy) under EKG and pulse oximetry monitoring. Subjects standing on the treadmill breathed through a mask. A continuous "ramp" protocol at constant grade $(1 \%)$ (starting from $8 \mathrm{~km} / \mathrm{h}$, increasing speed by $1 \mathrm{~km} / \mathrm{h}$ every 60 seconds) was used. The test was stopped when subjects complained of exhaustion. Exercise tolerance was evaluated as the maximal speed reached (Maximal Exercise Velocity: MEV), adjusted according to a modified Kuiper's equation (Equation 1) [34].

$$
M E V=v_{l}+\left(\frac{n}{6_{0}}\right)
$$

where $v_{l}$ represents the speed achieved at the last exercise step and $n$ the number of seconds attained during the last stage.

\section{Gas measurements}

The following variables were measured at peak exercise through breath by breath analysis of inhaled and exhaled gases, by mass flow meter and fast-responding gas analyzer (V-Max Encore, Yorba Linda, CA, USA): Oxygen uptake $\left(\dot{V} \mathrm{O}_{2}\right)$ and $\dot{V} \mathrm{O}_{2}$ normalized to body weight, and its relationship with heart rate (HR) (pulse oxygen or $\left.\dot{V} \mathrm{O}_{2} / H R\right), \mathrm{CO}_{2}$ production $\left(\dot{V} C_{2}\right)$, the physiological dead space to the tidal volume ratio $\left(V_{d} / V_{t}\right)$, minute ventilation $(\dot{V} E)$, maximal $\dot{V} E\left(\dot{V} E_{\text {max }}\right)$ expressed as the highest $\dot{V} E$ value recorded either during exercise or at the first time recovery phase, breathing respiratory reserve (BRR\% expressed as $\dot{V} E_{\max }$ to MVV ratio). The anaerobic threshold (AT) was estimated by $\mathrm{V}$ slope method and ventilatory equivalent method [35]. Anaerobic phase time (APT) was defined as the time spent during $\dot{V} \mathrm{CO}_{2} / \dot{V} \mathrm{O}_{2}>1$. Predicted values of $\mathrm{HR}$ were computed according to Tanaka et al. [36].

\section{Statistical analysis}

Subjects were categorized into four groups according to their role in the team as reported by the technical staff: forwards $(\mathrm{F})$, central midfielders $(\mathrm{CM})$, central defenders (CD), wide players (WP): goalkeepers were excluded from the study. According to MEV performed in the exercise test, players were divided into two groups (Hi-M: high-performers: able to run at a speed greater than median value of all subjects; Lo-M: low-performers: able to run at a speed lower than that median). Furthermore, the subjects were divided into two groups according to median $\dot{V} E_{\text {peak }}$ (Hi- $\dot{V} E$ and Lo- $\dot{V} E$, respectively).

Linear regression analyses between $\dot{V} E$ and $\dot{V} \mathrm{O}_{2}$, HR and $\dot{V} \mathrm{O}_{2}$, and HR and MEV, MEV and $\dot{V} \mathrm{O}_{2}$ were computed at peak exercise.

Two way analysis of variance (ANOVA) was carried out as follows: 1) dependent variable: $\dot{V} E_{\text {peak }}$; source of variation: role, MEV; 2) dependent variable: $\mathrm{FEV}_{1}$; source of variation: role, MEV. All pairwise multiple comparison procedures were carried out using Holm-Sidak method.

Student's t-test was used for analysing statistical significance of differences in the following parameters: $\dot{V} O_{2 p e a k}$, Body Mass Index (BMI), peak Respiratory Rate $\left(R R_{\text {peak }}\right)$, peak tidal volume $\left(V t_{\text {peak }}\right), \mathrm{MEV}$ and $\dot{V} \mathrm{O}_{2 \text { peak }} / H R_{\text {peak }}$ on $\mathrm{Hi}-\mathrm{M}$ vs Lo-M and Hi-VE vs Lo-VE, respectively.

Factor analysis was computed on the set of cardiovascular, metabolic, and respiratory variables measured at peak exercise using non-rotated Principal Component Analysis (PCA). PCA is a simple, non-parametric method 
of extracting relevant information from multivariate datasets. The central idea of PCA is to reduce the dimensionality of a dataset consisting of a large number of interrelated variables, while retaining the variation present in the dataset. This is achieved by transforming into a new variable set, the Principal Components (PCs) which are uncorrelated, and which are ordered so that the first few retain most of the variation present in all the original variables [37].

Multiple linear regression among variables resulting from PCA analysis was carried out. Correlation analysis between variables of interest was computed using Pearson coefficient.

Statistical analysis was carried out using SigmaStat version 3.5 (Systat Software, Inc., USA), except for factor analysis carried out using SPSS v10.1 (SPSS Inc. USA).

\section{Results}

Anthropometric, demographic, and resting physiological characteristics of the whole study population and according to exercise capacity are shown in Table 1 . The MEV median value was $18.65 \mathrm{~km} / \mathrm{h}$. BMI, height, weight, and age did not show any significant differences between $\mathrm{Hi}-\mathrm{M}$ and Lo-M. MVV and $\mathrm{FEV}_{1}$ were significantly higher in Hi-M than in Lo-M. There was no significant difference in anthropometric and demographic characteristics among different roles played.

Table 2 shows the physiological parameters at peak exercise according to exercise capacity. Only $\dot{\mathrm{V}} \mathrm{E}_{\text {peak }}$ was significantly higher in Hi-M than Lo-M, resulting from non significantly greater $\mathrm{Vt}_{\text {peak }}$ and $\mathrm{RR}_{\text {peak }}$, and non significantly lower $\mathrm{V}_{\mathrm{d}} / \mathrm{V}_{\mathrm{t}}$ in Hi-M than Lo-M subjects.

During the test, all players reached $97.9 \pm 4.7 \%$ of their predicted maximal HR without any significant difference between groups.

Table 3 shows resting and at peak exercise physiological characteristics according to $\dot{V} E_{\text {peak }}$. Median $\dot{V} E_{\text {peak }}$ was $153.05 \mathrm{~L} / \mathrm{min}$. Hi-VE showed significantly higher $\dot{\mathrm{V}} \mathrm{O}_{2 \text { peak }}, \dot{\mathrm{V}} \mathrm{O}_{2 \text { peak }} / \mathrm{HR}_{\text {peak }}, \mathrm{MEV}, \mathrm{BRR} \%, \mathrm{Vt}_{\text {peak }}$ and $\mathrm{FEV}_{1}$ than Lo-VE subjects.

Table 1 Anthropometric, demographic, and resting physiological characteristics of the whole study population and according to MEV values

\begin{tabular}{lcccc}
\hline & All & Hi-M $\mathbf{~}=\mathbf{4 5}$ & Lo-M $\mathbf{~}=\mathbf{4 5}$ & $\mathbf{p}$ \\
\hline BMI $\left[\mathbf{K g} / \mathbf{m}^{\mathbf{2}}\right]$ & $23.8 \pm 1.2$ & $23.6 \pm 1.4$ & $24.0 \pm 0.9$ & 0.1326 \\
Height $[\mathbf{c m}]$ & $181.8 \pm 5.2$ & $184.0 \pm 4.9$ & $182.6 \pm 5.2$ & 0.059 \\
Weight $[\mathbf{K g}]$ & $79.4 \pm 5.5$ & $80.0 \pm 5.6$ & $78.8 \pm 5.3$ & 0.3221 \\
Age [years] & $25.9 \pm 4.0$ & $25.2 \pm 3.5$ & $26.6 \pm 4.4$ & 0.0969 \\
MVV [L/m] & $201.1 \pm 21.7$ & $206.6 \pm 20.4$ & $195.6 \pm 21.6$ & 0.0155 \\
FEV $_{\mathbf{1}}[\mathbf{L}]$ & $5.0 \pm 0.5$ & $5.2 \pm 0.5$ & $4.9 \pm 0.5$ & 0.0152 \\
\hline
\end{tabular}

Values expressed are shown as mean \pm SD. Abbreviations as reported in the text.
Table 2 Physiological parameters at peak exercise of subjects according to MEV

\begin{tabular}{|c|c|c|c|c|}
\hline & All & $\mathrm{Hi}-\mathrm{M} \mathrm{n}=45$ & Lo-M $n=45$ & $p$ \\
\hline MEV $[\mathrm{km} / \mathrm{h}]$ & $18.5 \pm 1.1$ & $19.4 \pm 0.6$ & $17.6 \pm 0.7$ & 0.0000 \\
\hline$\dot{\mathrm{V}} \mathrm{E}_{\text {peak }}[\mathrm{L} / \mathrm{min}]$ & $151.7 \pm 19.4$ & $156.2 \pm 19.8$ & $147.1 \pm 17.9$ & 0.0249 \\
\hline$\left(V_{d} / V_{t}\right)_{\text {peak }}$ & $0.10 \pm 0.03$ & $0.09 \pm 0.04$ & $0.11 \pm 0.03$ & 0.0548 \\
\hline $\mathrm{RR}_{\text {peak }}[$ breaths/min] & $53.3 \pm 4.9$ & $54.5 \pm 5.1$ & $52.6 \pm 4.6$ & 0.0773 \\
\hline$V t_{\text {peak }}[\mathrm{L} / \mathrm{min}]$ & $2.87 \pm 0.45$ & $2.92 \pm 0.42$ & $2.84 \pm 0.46$ & 0.3848 \\
\hline $\mathrm{HR}_{\text {peak }}[\mathrm{b} / \mathrm{min}]$ & $186.0 \pm 9.5$ & $186.2 \pm 9.6$ & $185.7 \pm 9.4$ & 0.7911 \\
\hline$\dot{\mathrm{vO}} \mathrm{O}_{\text {peak }}[\mathrm{mL} / \mathrm{min} / \mathrm{Kg}]$ & $63.3 \pm 5.3$ & $63.3 \pm 5.3$ & $63.2 \pm 5.4$ & 0.9359 \\
\hline BRR[L] & $41.9 \pm 20.8$ & $42.8 \pm 20.1$ & $41.0 \pm 21.4$ & 0.6726 \\
\hline BRR\% & $79.0 \pm 9.3$ & $79.1 \pm 9.5$ & $78.8 \pm 9.1$ & 0.8750 \\
\hline
\end{tabular}

Values are shown as mean \pm SD. Abbreviations as reported in the text.

$\dot{V} E_{\text {peak }}$ was significantly correlated to $\dot{V} O_{2 p e a k}(\mathrm{r}=0.619$, $\mathrm{p}=0.001$ ) (Figure 1 ) and MEV was significantly correlated to $\dot{V} O_{2 p e a k}(\mathrm{r}=0.267, \mathrm{p}=0.011)$. No statistical significant correlation was found between $H R_{\text {peak }}$ and MEV.

A weak, although significant correlation between $V_{d} / V_{t}$ and $\dot{V} E$ at peak exercise was found in all players $(\mathrm{r}=-0.282 ; \mathrm{p}=0.007)$. No significant differences in $\dot{V}$ $\mathrm{O}_{2 \text { peak }}, \mathrm{MEV}$ and BRR were found among different roles, whereas mean MVV was significantly lower in $\mathrm{F}$ than in CM $(193.3 \pm 21.2$ vs $206.1 \pm 19.9$ liters respectively, $\mathrm{p}=0.043)$. ANOVA showed that the difference in the mean value of $\dot{V} E_{\text {peak }}$ and $F E V_{1}$ among the different levels of role of players was not significantly different after allowing for the effects of differences in MEV ( $p=0.377$ and $\mathrm{p}=0.543$, respectively).

Factor analysis using the PCA on the variables measured at peak exercise and at rest was carried out. Table 4

Table 3 Resting and at peak exercise physiological characteristics of subjects according to $\dot{V} E_{\text {peak }}$ values

\begin{tabular}{|c|c|c|c|}
\hline & $\mathrm{Hi}-\mathrm{VE} \mathrm{n}=45$ & Lo-VE $n=45$ & $p$ \\
\hline MEV $[\mathrm{km} / \mathrm{h}]$ & $18.9 \pm 0.9$ & $18.1 \pm 1.2$ & 0.0008 \\
\hline$\dot{\mathrm{V}} \mathrm{E}_{\text {peak }}[\mathrm{L} / \mathrm{min}]$ & $166.3 \pm 10.4$ & $137.1 \pm 14.8$ & 0.0000 \\
\hline$\left(V_{d} / V_{t}\right)_{\text {peak }}$ & $0.09 \pm 0.03$ & $0.10 \pm 0.03$ & 0.0741 \\
\hline $\mathrm{RR}_{\text {peak }}[$ breaths/min $]$ & $53.8 \pm 5.1$ & $52.7 \pm 4.6$ & 0.2617 \\
\hline $\mathrm{Vt}_{\text {peak }}[\mathrm{L} / \mathrm{min}]$ & $3.11 \pm 0.31$ & $2.62 \pm 0.34$ & 0.0000 \\
\hline$H R_{\text {peak }}[b / \min ]$ & $185.8 \pm 8.9$ & $186.1 \pm 10.0$ & 0.8946 \\
\hline$\dot{\mathrm{V}} \mathrm{O}_{2 \text { peak }} / \mathrm{HR}_{\text {peak }}[\mathrm{mL} / \mathrm{min} / \mathrm{bb}]$ & $28.3 \pm 4.0$ & $25.4 \pm 3.8$ & 0.0004 \\
\hline$\dot{\mathrm{VO}}_{2 \text { peak }}[\mathrm{mL} / \mathrm{min} / \mathrm{Kg}]$ & $65.7 \pm 4.4$ & $60.8 \pm 5.3$ & 0.0000 \\
\hline BRR[L] & $34.5 \pm 18.0$ & $49.3 \pm 20.8$ & 0.0006 \\
\hline BRR\% & $83.4 \pm 7.8$ & $74.6 \pm 8.7$ & 0.0000 \\
\hline $\mathrm{RR}_{\text {peak }}\left[\dot{V} \mathrm{CO}_{2} / \dot{V} \mathrm{O}_{2}\right]$ & $1.08 \pm 0.17$ & $1.10 \pm 0.10$ & 0.4576 \\
\hline MVV[L/min] & $208.0 \pm 18.0$ & $194.2 \pm 22.9$ & 0.0020 \\
\hline $\mathrm{FEV}_{1}[\mathrm{~L}]$ & $5.2 \pm 0.4$ & $4.8 \pm 0.6$ & 0.0021 \\
\hline
\end{tabular}

Values are shown as mean \pm SD. Abbreviations as reported in the text. 


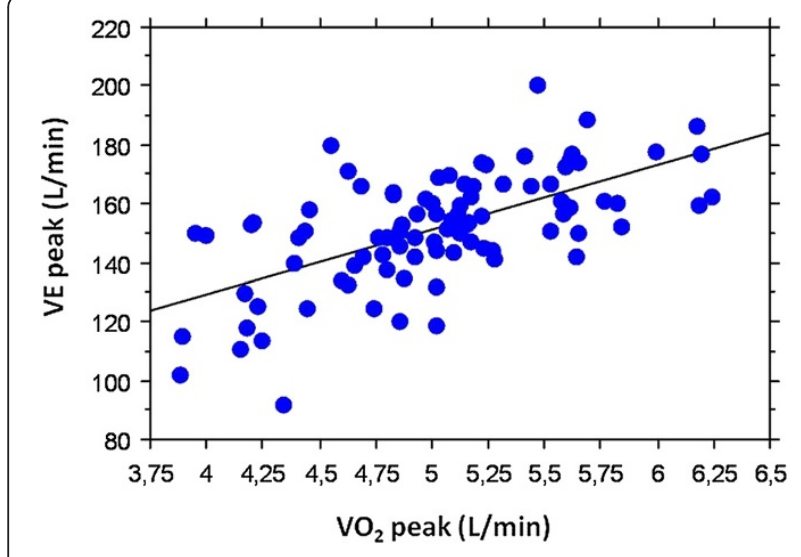

Figure 1 Relationship between minute ventilation and oxygen uptake at peak exercise as shown by the equation: $V E_{\text {peak }}=$ $41.76+\left(21.88 * V_{2 \text { peak }}\right) r=0.619, p<0.001$.

reports the distribution along the first three components of the following variables: $\dot{V} E_{\text {peak }}, \dot{V} O_{2 \text { peak }},\left(V_{d} / V_{t}\right)_{\text {peak }}$, $H R_{\text {peak }}, \mathrm{BRR}_{\text {peak }}, \mathrm{RR}_{\text {peak }}, \dot{V} \mathrm{O}_{2 \text { peak }} / H R_{\text {peak }}, \mathrm{FEV}_{1}$. The first three components accounted for $74.33 \%$ of cumulative variance. Multiple linear regression on most representative variables on each component deriving from PCA at peak exercise is represented by the following equation:

$$
\begin{aligned}
V O_{2 p e a k}= & 1.748+\left(0.012 \times V E_{\text {peak }}\right) \\
& +\left(0.299 \times F E V_{1}\right)-(0.003 \times B R R) R \\
= & 0.641 p<0.05
\end{aligned}
$$

Equation (2) represents a statistically significant relationship between $V O_{2 p e a k}$ and $V E_{\text {peak }}, F E V_{1}$ and $B R R$.

\section{Discussion}

The novelty of this study is represented by the analysis of ventilatory parameters as evaluation tool of professional soccer players performance. Our elite soccer players were evaluated during seasonal activity. The main finding of

\begin{tabular}{|c|c|c|c|}
\hline & \multicolumn{3}{|c|}{ Component } \\
\hline & 1 & 2 & 3 \\
\hline$\dot{\mathrm{VO}}_{2 \text { peak }}$ & 0.950 & 0.014 & 0.081 \\
\hline$\dot{\mathrm{VO}}_{2 \text { peak }}$ & 0.859 & -0.217 & -0.088 \\
\hline$\dot{V}_{2 \text { peak }} / \mathrm{HR}_{\text {peak }}$ & 0.853 & -0.182 & 0.305 \\
\hline$\dot{\mathrm{V}} \mathrm{E}_{\text {peak }}$ & 0.720 & 0.147 & -0.518 \\
\hline $\mathrm{RR}_{\text {peak }}$ & -0.305 & 0.362 & -0.665 \\
\hline$H R_{\text {peak }}$ & -0.180 & 0.406 & -0.304 \\
\hline BRR & -0.197 & 0.675 & 0.688 \\
\hline$\left(V_{d} / V_{t}\right)_{\text {peak }}$ & -0.341 & -0.545 & 0.301 \\
\hline $\mathrm{FEV}_{1}$ & 0.432 & 0.817 & 0.214 \\
\hline
\end{tabular}
our study is that $\dot{\mathrm{V}} \mathrm{E}_{\text {peak }}$ and $\mathrm{FEV}_{1}$ but not $\dot{\mathrm{V}} \mathrm{O}_{2 \text { peak }}$ are

Table 4 PCA component matrix (peak values) the main determinants for discriminating high and low performers: nevertheless, neither Hi-M nor Lo-M were ventilatory limited. Therefore, our results are in agreement with available literature about elite athletes: the main limitation to maximal performance is represented by cardiovascular limit. Furthermore, our data highlight the key role of resting dynamic ventilatory parameters like $\mathrm{FEV}_{1}$ as predictive factor of maximal exercise capacity, indicating the need to include lung function test in the routine evaluation of these elite soccer players.

In our study population measured $\dot{V} O_{2 p e a k}$ is in agreement with average values reported in previous studies on international elite soccer players [11]. Currently, ventilatory parameters are poorly investigated in these athletes and our study provides a contribution to this field.

Significant relationships between $\dot{V} E_{\text {peak }}, \mathrm{FEV}_{1}$ and BRR with exercise capacity were found, and these parameters were significantly different between high and low performers. This finding offers a new insight in this field as it provides a quantitative relationship between dynamic ventilatory parameters and exercise performance in these athletes. Indeed, $\dot{V} O_{2 p e a k}$ described by a linear combination of most representative ventilatory parameters resulting by PCA analysis (i.e., $\dot{V} E_{\text {peak }}, \mathrm{FEV}_{1}$ and BRR) corresponds to a physiological relationship among these variables. Therefore, the physiological parameters obtained from a simple test like spirometry might be used to distinguish high from low performers.

The significant correlation found between $\left(V_{d} / V_{t}\right)_{\text {peak }}$ and $\dot{V} E_{\text {peak }}$ on the whole study population represents an interesting finding: high values of $\dot{V} E_{\text {peak }}$ found in $\mathrm{Hi}-\mathrm{M}$ elite soccer athletes correspond to low values of $\left(V_{d} / V_{t}\right)_{\text {peak }}$. High ventilatory efficiency is more important in achieving better performance than VE. These parameters depend also on anthropometric and demographic characteristics which in our study were not significantly different between groups of players, independently of exercise capacity, ventilatory capacity, or role played.

Our study did not find any significant difference in physiological parameters among different playing roles. This may be related to lack of specific training among the roles.

\section{Limitation of the study}

The subjective reason to stop exercise, either dyspnoea, muscular fatigue or both, was not recorded, despite most subjects informally reported muscular fatigue. This is not surprising given the lack of ventilatory limitation to exercise shown by these athletes.

\section{Conclusions}

Respiratory parameters can play a determinant role in qualitative and quantitative evaluation of professional 
soccer players performance as it was confirmed by results discussed so far. Further studies should be addressed to investigate the impact of different training programmes on dynamic ventilatory parameters.

\section{Competing interests}

The authors declare that they have no competing interests.

\section{Authors' contributions}

ADP conceived the study, participated in its design, collected data and helped to draft the manuscript. SM participated in the design of the study, performed the statistical analysis and helped to draft the manuscript. GAC and MLM participated in the design of the study. GV participated in the design of the study and performed the statistical analysis. NA coordinated the study and helped to draft the manuscript. All authors read and approved the final manuscript.

\section{Acknowledgments}

Special thanks to ACF Fiorentina, Genoa CFC, Lecce Calcio, Napoli SSC, AC Milan, US Città di Palermo soccer teams.

\section{Author details}

${ }^{1}$ Pulmonary Rehabilitation and Weaning Center, Auxilium Vitae, Volterra, Pisa, Italy. ${ }^{2}$ Rehabilitation Bioengineering Laboratory, ScuolaSuperioreSant'Anna and Auxilium Vitae, Volterra, Italy. ${ }^{3}$ Institute of Clinical Physiology, G. Monasterio Foundation/Clinical Research Council Pisa, Pisa, Italy. ${ }^{4}$ The BioRobotics Institute, Scuola Superiore Sant'Anna, Pisa, Italy. ${ }^{5}$ Physical Education, Sport and Health, University of Florence, Florence, Italy.

Received: 17 December 2013 Accepted: 12 February 2014

Published: 2 April 2014

\section{References}

1. Bradley PS, Sheldon W, Wooster B, Olsen P, Boanas P, Krustrup P: High-intensity running in English FA premier league soccer matches. J Sports Sci 2009, 27:159-168.

2. Bradley PS, Di Mascio M, Peart D, Sheldon B: High-intensity activity profiles of elite soccer players at different performance levels. J Strength Cond Res 2010, 24:2343-2351.

3. Di Salvo V, Pigozzi F, González-Haro C, Laughlin MS, De Witt JK: Match performance comparison in Top English soccer leagues. Int J Sports Med 2013, 34:526-532.

4. Gregson W, Drust B, Atkinson G, Salvo VD: Match-to-match variability of highspeed activities in premier league soccer. Int I Sports Med 2010, 31:237-242.

5. Osgnach C, Poser S, Bernardini R, Rinaldo R, di Prampero PE: Energy cost and metabolic power in elite soccer: a new match analysis approach. Med Sci Sports Exerc 2010, 42:170-178.

6. Hoff J: Training and testing physical capacities for elite soccer players. J Sports Sci 2005, 23:573-582.

7. Kemi OJ, Hoff J, Engen LC, Helgerud J, Wisløff U: Soccer specific testing of maximal oxygen uptake. J Sports Med Phys Fitness 2003, 43:139-144.

8. Oberacker LM, Davis SE, Haff GG, Witmer CA, Moir GL: The Yo-Yo IR2 test: physiological response, reliability, and application to elite soccer. J Strength Cond Res 2012, 26:2734-2740.

9. Svensson M, Drust B: Testing soccer players. J Sports Sci 2005, 23:601-618.

10. Lago-Peñas C, Casais L, Dellal A, Rey E, Dominguez E: Anthropometric and physiological characteristics of young soccer players according to their playing positions: relevance for competition success. I Strength Cond Res 2011, 25:3358-3367.

11. Sporis G, Jukic I, Ostojic SM, Milanovic D: Fitness profiling in soccer: physical and physiologic characteristics of elite players. J Strength Cond Res 2009, 23:1947-1953.

12. Da Silva JF, Guglielmo LG, Bishop D: Relationship between different measures of aerobic fitness and repeated-sprint ability in elite soccer players. J Strength Cond Res 2010, 24:2115-2121.

13. Nassis GP, Geladas ND, Soldatos Y, Sotiropoulos A, Bekris V, Souglis A: Relationship between the 20-m multistage shuttle run test and 2 soccer-specific field tests for the assessment of aerobic fitness in adult semi-professional soccer players. J Strength Cond Res 2010, 24:2693-2697.
14. Castagna C, Manzi V, Impellizzeri F, Weston M, Barbero Alvarez JC: Relationship between endurance field tests and match performance in young soccer players. J Strength Cond Res 2010, 24:3227-3233.

15. Mohr M, Krustrup P, Bangsbo J: Match performance of high-standard socce players with special reference to development of fatigue. J Sports Sci 2003, 21:519-528.

16. Bangsbo J: The physiology of soccer-with special reference to intense intermittent exercise. Acta Physiol Scand 1994, 15(suppl 619):1-156.

17. Bangsbo J, Mohr M, Krustrup P: Physical and metabolic demands of training and match-play in the elite football player. J Sports Sci 2006, 24:665-674.

18. Bangsbo J, laia FM, Krustrup P: Metabolic response and fatigue in soccer. Int J Sports Physiol Perform 2007, 2:111-127.

19. Gatterer H, Faulhaber M, Patterson C: Real time VO2 measurements during soccer match-play. J Sports Med Phys Fitness 2010, 50:109-110.

20. Stølen T, Chamari K, Castagna C, Wisløff U: Physiology of soccer: an update. Sports Med 2005, 35:501-536.

21. Ekstrand J, Waldén M, Hägglund M: A congested football calendar and the wellbeing of players: correlation between match exposure of European footballers before the World Cup 2002 and their injuries and performances during that World Cup. Br I Sports Med 2004, 38:93-97.

22. Hoff J, Wisløff U, Engen LC, Kemi OJ, Helgerud J: Soccer specific aerobic endurance training. Br J Sports Med 2002, 36:218-221.

23. Baldari C, Videira M, Madeira F, Sergio J, Guidetti L: Lactate removal during active recovery related to the individual anaerobic and ventilatory thresholds in soccer players. Eur J Appl Physiol 2004, 93:224-230.

24. Boone J, Vaeyens R, Steyaert A, VandenBossche L, Bourgois J: Physical fitness of elite Belgian soccer players by player position. J Strength Cond Res 2012, 26:2051-2057.

25. Casajús JA: Seasonal variation in fitness variables in professional soccer players. J Sports Med Phys Fitness 2001, 41:463-469.

26. Kalapotharakos VI, Ziogas G, Tokmakidis SP: Seasonal aerobic performance variations in elite soccer players. J Strength Cond Res 2011, 25:1502-1507.

27. Marques-Neto SR, Maior AS, MaranhãoNeto GA, Santos EL: Analysis of heart rate deflection points to predict the anaerobic threshold by a computerized method. J Strength Cond Res 2012, 26:1967-1974.

28. Metaxas TI, Koutlianos NA, Kouidi EJ, Deligiannis AP: Comparative study of field and laboratory tests for the evaluation of aerobic capacity in soccer players. J Strength Cond Res 2005, 19:79-84.

29. McMillan K, Helgerud J, Grant SJ, Newell J, Wilson J, Macdonald R, Hoff J: Lactate threshold responses to a season of professional British youth soccer. Br J Sports Med 2005, 39:432-436.

30. Tønnessen E, Hem E, Leirstein S, Haugen T, Seiler S: Maximal aerobic power characteristics of male professional soccer players, 1989-2012. Int J Sports Physiol Perform 2013, 8:323-329.

31. Ziogas GG, Patras KN, Stergiou N, Georgoulis AD: Velocity at lactate threshold and running economy must also be considered along with maximal oxygen uptake when testing elite soccer players during preseason.J Strength Cond Res 2011, 25:414-419.

32. ATS/ERS Task Force Standardisation of Lung Function Testing: General consideration for lung function testing. Eur Respir J 2005, 26:153-161.

33. Campbell SC: A comparison of the maximum volume ventilation with forced expiratory volume in one second: an assessment of subject cooperation. J Occup Med 1982, 24:531-533.

34. Kuipers H, Verstappen FT, Keizer HA, Geurten P, van Kranenburg G: Variability of aerobic performance in the laboratory and its physiologic correlates. Int I Sports Med 1985, 6:197-201.

35. Wasserman K, Hansen JE, Sue DY, Stringer WW, Whipp BJ: Principles of Exercise Testing and Interpretation, Volume chapter 4. Fourth edition. Philadelphia: Lippincott Williams and Wilkins; 2005:87-90.

36. Tanaka H, Monahan KD, Seals DR: Age-predicted maximal heart rate revisited. J Am Coll Cardiol 2001, 37:153-156.

37. Jolliffe IT: Introduction. In Principal Component Analysis. 2nd edition. Edited by Bickel P, Diggle P, Fienberg S, Krickeberg K, Olkin I, Wermuth N, Zege S. New York: Springer: 2002:1-9.

doi:10.1186/2049-6958-9-20

Cite this article as: Di Paco et al: Ventilatory response to exercise of elite soccer players. Multidisciplinary Respiratory Medicine 2014 9:20. 